\title{
NEED FOR PROCEDURAL SKILLS TRAINING IN UNDERGRADUATE EDUCATION
}

Ibrahim Sulaiman* MD, Pamela J Morgan* MD, FRCPC, Doreen Cleave-Hogg ${ }^{\Psi}$ PhD, Susan DeSousa BSc, RRCP* Michèle Haley BA** Department of Anesthesia, Sunnybrook \& Women's College Health Sciences Centre, 7 6Grenville St. Toronto, Ontario M5S 1B2, ${ }^{\Psi}$ Wilson Centre for Research in Education, University of Toronto, 200 Elizabeth St. Eaton Wing South, Room 565 University Health Network, Toronto, Ontario M5G 2C4

\section{INTRODUCTION}

The literature has suggested that medical students are not receiving adequate exposure to clinical skills. This study was designed to enumerate students' procedural skills exposure and to provide them with training using both part-task and high-fidelity simulation in the Canadian Simulation Centre for Human Performance and Crisis Management Training.

\section{METHODS}

After research ethics board approval and informed consent, final year medical students were asked to complete an entry questionnaire to indicate the number of opportunities they had to perform specific procedural tasks during their clerkship. They were then given an orientation to the Simulation Centre. Five teaching stations were presented, each accompanied by a set of learning objectives. These stations were: 1) patient monitoring (Datex light portable monitor); 2) intravenous catheterization (Laerdal IV training arms); 3) bag-mask ventilation and endotracheal intubation (Laerdal Airway Management Trainer); 4 )laryngeal mask insertion (METI AirSim); and 5) high-fidelity simulation experience focusing on the induction and maintenance of general anesthesia and management of a clinical scenario using a MedSim high-fidelity simulator.

\section{RESULTS}

Interim data of entry questionnaires from 82 students were analyzed. Results are expressed as \% student exposure to the procedural task. (Table 1)

\begin{tabular}{|l|c|c|c|c|}
\hline N=82 & \multicolumn{4}{|c|}{ \# of opportunities (\%) } \\
Procedural tasks & 0 & $1-10$ & $11-20$ & $>20$ \\
\hline 1. Pulse oximetry & 1.2 & 28.0 & 18.3 & 52.4 \\
\hline 2. EKG monitoring & 3.7 & 451 & 18.3 & 32.9 \\
\hline 3. Non-invasive BP monitoring & 49 & 23.2 & 146 & 573 \\
\hline 4 .End-tidal capnography & 476 & 35.4 & 3.7 & 12.2 \\
\hline 5. IV catheterization & 28.0 & 573 & 2.4 & 12.2 \\
\hline 6.Standard anesthesia induction agents & 622 & 24.4 & 3.7 & 98 \\
\hline 7.LMA insertion & 622 & 268 & 61 & 49 \\
\hline 8. ETT insertion & 646 & 195 & 61 & 98 \\
\hline
\end{tabular}

\section{DISCUSSION}

These data indicate students' minimal exposure to a number of procedural skills and support the need for enhanced procedural skills training in undergraduate medical education. Part-task and high-fidelity simulation provide the means to acquire experience and competency in a variety of technical skills in a no-risk, reproducible and controlled environment. 